\title{
Diagnostic approach in assessment of a ferroresonant circuit
}

\author{
Łukasz Majka ${ }^{1}$ (D) Maciej Klimas ${ }^{1}$ \\ Received: 7 December 2018 / Accepted: 11 March 2019 / Published online: 23 March 2019 \\ (c) The Author(s) 2019
}

\begin{abstract}
This paper presents possibilities offered by a diagnostic system called FeD. The system is completely original; it has been developed by the authors on the basis of Arduino platform. The system has been designed to perform and record measurements and to carry out different numerical operations. The real-time function for several operations is incorporated in this system. The necessary input data for the system consist of the electrical voltage waveforms only. Rescaled voltage quantities can be displayed, measured, recorded or computed in any chosen way. The system has been developed particularly for measurements and computations in the ferroresonant circuits. The strongest part of the system is its versatility. It works with a standard PC and supports a universal connection (USB standard). This is undeniably a cost-wise solution. Driving and control of the system functions are carried out using the authors' original software implemented in SciLab environment. This is free software, similar to and compatible with other existing CAD programs such as Octave and MATLAB. The obtained data, scripts and results can be freely transferred between them. The program is equipped with a transparent GUI. The need of constructing a special system to diagnose the ferroresonant circuit has emerged during earlier ferroresonance analyses and computations. Every ferroresonant circuit requires specific kind of diagnostics to estimate and display its base features in order to determine the best scientific approach to the problem. The ferroresonance phenomenon belongs to the domain of nonlinear problems. Its analysis requires excellent skills in mathematics and physics as well as computer science. Moreover, this subject also requires specialized engineering knowledge, particularly in the field of power engineering and power system equipment. Modern mathematical models and analyses used in ferroresonant computations are quite accurate; however, in case of a common user, they are often difficult to understand or implement. This paper provides full description of construction, features and test results of the developed hardware/software system designed for diagnostics of ferroresonant circuits. The test circuit case study has been performed in the entire power supply range. Results of measurements and computations as well as screenshots captured from authors' original software are shown in different figures. The developed software and recorded data have been finally used in modeling and further simulations. During this, the application of the fractional derivative iron core coil model to ferroresonance analysis has been shown. The waveforms obtained from computer simulations have been compared with those obtained from measurements performed in the test circuit.
\end{abstract}

Keywords Ferroresonance $\cdot$ Power system · Ferromagnetic core coil · Arduino · Measurement verification · Fractional derivative $\cdot$ Mathematical modeling and parameter estimation $\cdot$ Digital signal processing $\cdot$ State space and plane representation of dynamical systems

\section{Introduction}

Ferroresonance is a phenomenon characterized by its unpredictable and aggressive nature. It is a great threat especially when it occurs in electrical distribution systems. It appears after transient disturbances (transient overvoltage, lightning

Łukasz Majka

lukasz.majka@polsl.pl

1 Silesian University of Technology, Akademicka 10, 44-100 Gliwice, Poland overvoltage or temporary fault) or switching operations (transformer energizing or fault clearing). Its effects are characterized by high sustained overvoltages and overcurrents with maintained levels of current and voltage waveform distortion. In high-voltage and current circuits (MV and HV networks), its consequences practically always include massive and expensive damage $[1,2]$.

The reason why ferroresonance so widely affects power system circuits is due to dense accumulation of the transformers' saturable inductances and the capacitive effects of power 
Fig. 1 Photograph of laboratory setup (a) and scheme (b) (a)

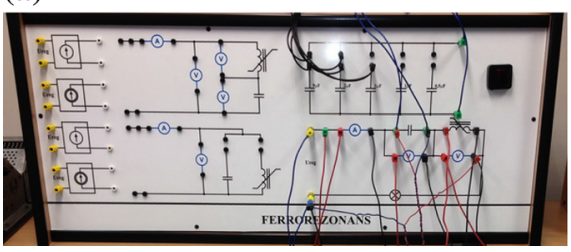

(b)

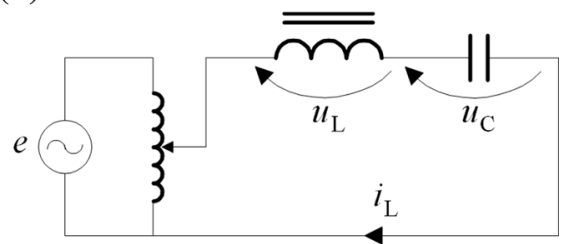

transmission and protective elements set in low resistance systems (low-loss transformers, unloaded transformers, low circuit losses) [3,4].

Nevertheless, the ferroresonance phenomenon depends also on many other factors and circumstances such as initial conditions of the system, transformer iron core saturation curve, residual fluxes in the transformer core, type of transformer winding arrangement, capacitance of the circuit, point-of-wave switching operation or total losses. So its predictability may be considered as quite complex and difficult [1,5-7].

The nature of a phenomenon described above and referred to in many research papers [4,8-16] leaves no doubt as to the constant need of studying low-loss circuits containing capacitors and saturable inductors. Taking into account their tendency to become prone to ferroresonance condition, a new and interesting approach to the problem focuses on developing of new detection, diagnostic and monitoring procedures.

\section{Characteristics of the test circuit}

A specially designed laboratory setup has been used. It contains a voltage and current source, both controlled over a wide range. There is also a linear capacitor in the circuit, and its total value may be modified by applying different capacitors for series and parallel configurations. The main element of the circuit is iron core coil. The circuit configuration allows free access to terminals of each element.

For the test purpose, the series configuration has been chosen. Photograph of the setup and its scheme are depicted in Fig. 1.

Despite an apparent simplicity of the proposed test circuit, a ferroresonance effect may be induced in it. The series ferroresonant circuit implemented in the laboratory is equipped with carefully selected elements and supplied with a controlled sinusoidal voltage. The phenomenon of ferroresonance is induced in a controlled manner and on a safe scale, so there is no danger of damage to circuit elements. Moreover, a presented (R)LC circuit structure may be later adapted to many problems emerging when power system is modeled. The designed RLC circuit constitutes a fragment of simplified model of a power system $[3,4,8,13]$.

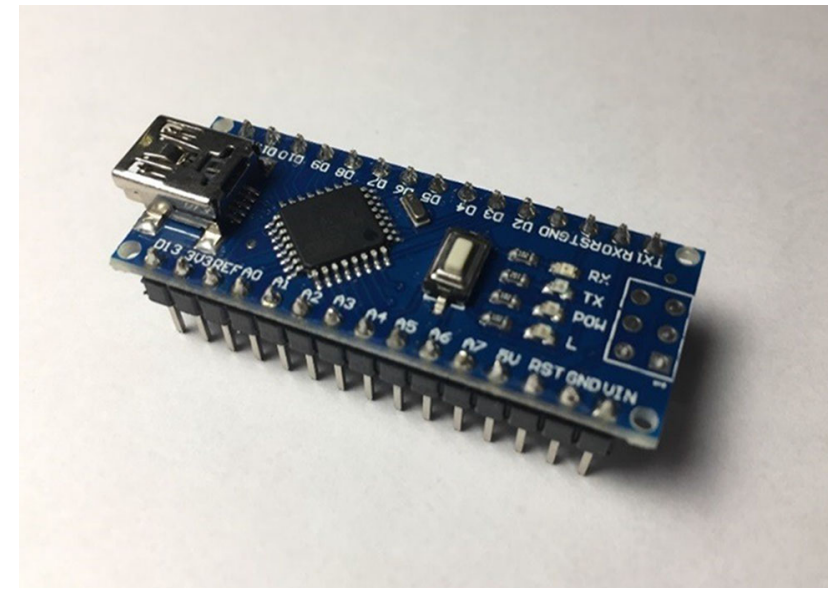

Fig. 2 Photograph of Arduino Nano system

\section{Characteristics of the measurement platform}

The necessity of constructing a special system to diagnose the ferroresonant circuit has emerged during earlier ferroresonance analysis and computations. Previous investigations $[17,18]$ have shown that dealing with such problem like ferroresonance requires prior diagnosis of the ferroresonant circuit-performed separately for every circuit—in order to determine best scientific approach to the problem. Authors have assumed that the developed diagnostics unit should be a combination of all known tools and meters, using up-to-date data acquisition and processing technology. Moreover, some features should be accessible on real-time basis (online). Application of a universal way of communication (USB) is beyond discussion.

Among the various microcontrollers available on the market, the most popular systems come from manufacturers such as Microchip Technology, STMicroelectronics, Atmel and Freescale Semiconductor, Texas Instruments and Analog Devices. The developed measuring system uses Arduino solutions [19], namely Arduino Nano. It is equipped with the AVR microcontroller ATmega328 [20]. A photograph of the system is presented in Fig. 2.

Short summary of its main possibilities and features is given in Table 1.

The chosen measuring unit operates in very specific and small range of voltages (Table 1). The tested circuit has to be 
Table 1 Main parameters of Arduino Nano system

\begin{tabular}{ll}
\hline Operating voltage & $5 \mathrm{~V}$ \\
SRAM & $2 \mathrm{~KB}$ \\
Clock speed & $16 \mathrm{MHz}$ \\
Analog IN pins & 8 \\
Input voltage & $7-12 \mathrm{~V}$ \\
Power consumption & $19 \mathrm{~mA}$ \\
\hline
\end{tabular}

separated from the Arduino system, and the signals need to be rescaled. Therefore, additional separating block has been developed and maximum of its operating range has been set at $400 \mathrm{~V}$.

Figure 3 shows the block diagram of signal rescale process. The manufactured prototype of the additional separating unit is shown in Fig. 4.

All signal processing operations require verification, in particular those carried out in additional separating block. The certified industrial digital disturbance recorder RZ1 (Kared Gdańsk) [21] was used in calibration and authentica- tion process. The photograph of complete diagnostics system FeD connected to the laboratory setup is depicted in Fig. 5.

\section{Original control program}

The use of computers in scientific research often requires specialized non-standard software. One of the basic applications is the computerized operation of measuring apparatus. Non-standard software is particularly useful where novel and original equipment is used. As a result, a computer with such software is used to receive electronic signals, collect data, record measurement results, create and run databases or perform specific procedures, calculations and other activities [22-26].

Lots of test results are obtained in particular by dynamic measurements (carried out on a continuous basis). Activities such as recording, calculating and interpreting result in a manual manner can be difficult or even impossible. Hence, the necessity of using IT solutions.

The interface of the authors' original control program of the elaborated measurement system is shown in Fig. 6. The
Fig. 3 Block scheme of signal rescale process

Fig. 4 Photograph of manufactured prototype of the additional separating unit during tests
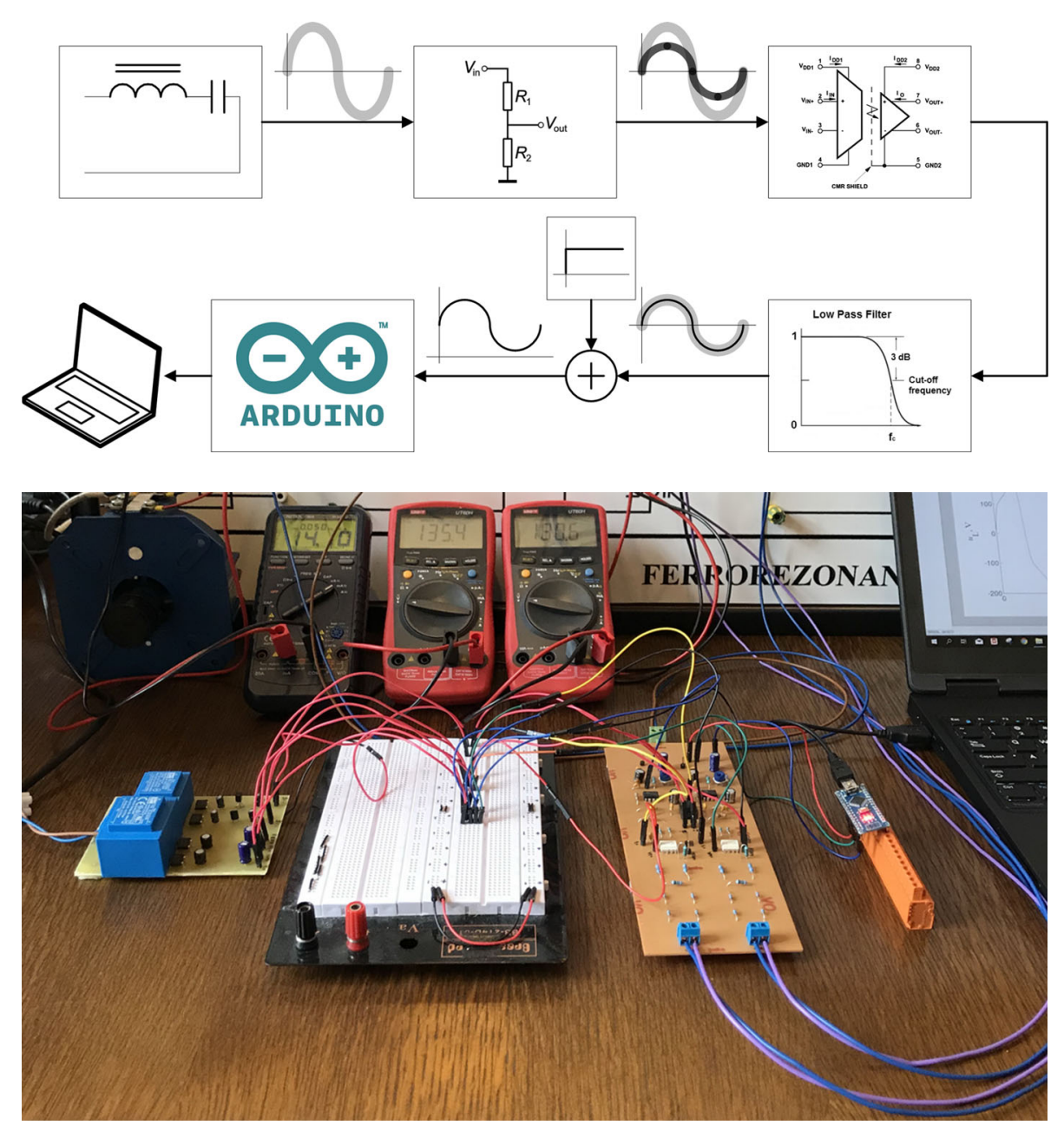
Fig. 5 Photograph of complete diagnostics system FeD connected to the laboratory setup
Fig. 6 View of the interface window in the SciLab environment
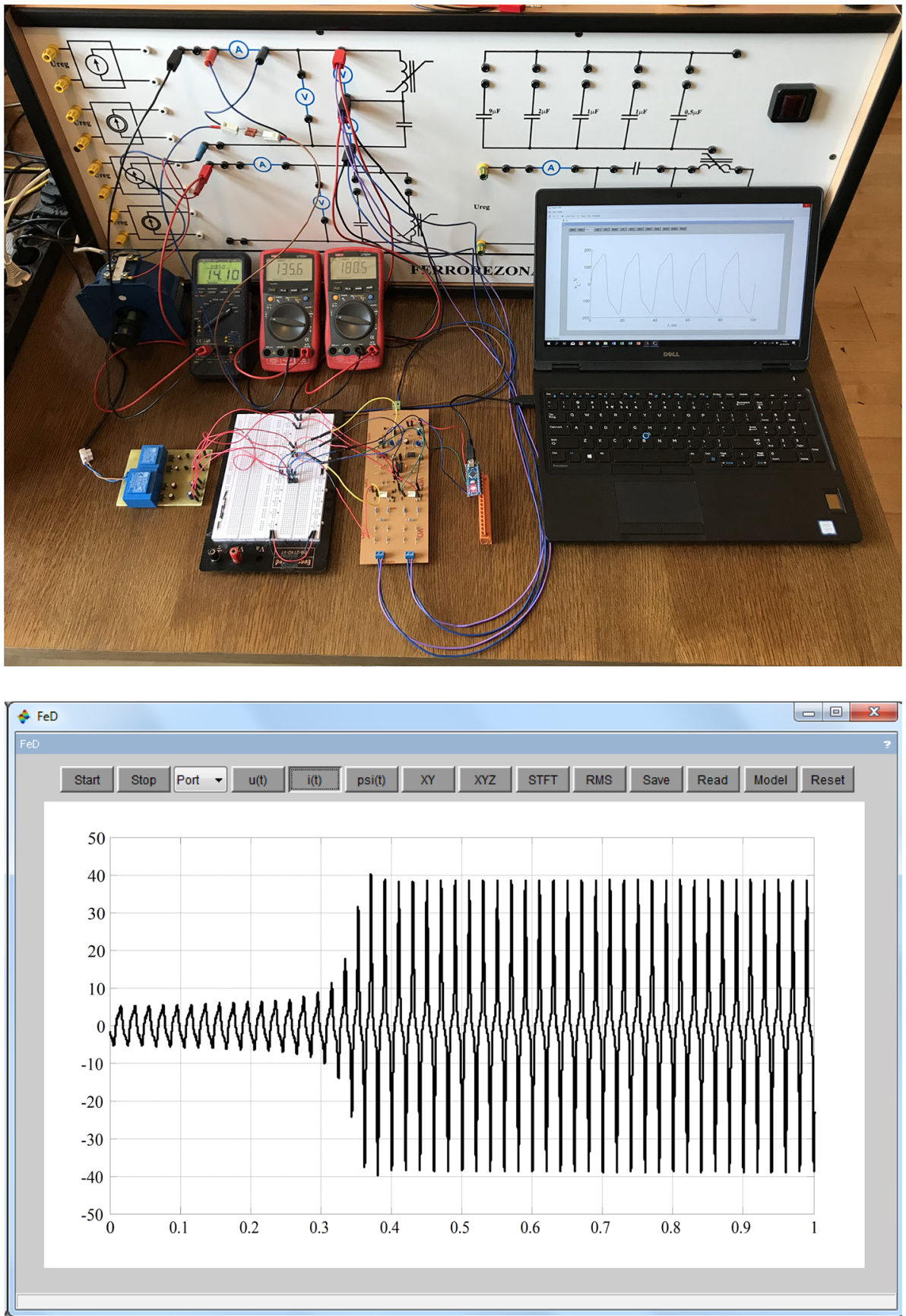

program has been written in the SciLab environment, which shows exceptional compatibility with the Arduino hardware platform.

Execution of the program is performed with the help of numerous buttons, and detailed descriptions are provided for each one. The offered options are previews of $u-i$ waves for all circuit elements, True RMS measurements with their previews, preview of waveforms calculated from given patterns (i.e., flux, circuit and coil losses), performing advanced computing (STFT analysis) with visualization of results, data recording and exporting options, plotting characteristics and
2D/3D graphs from stored data, etc. The diagram of the functional structure of the program is shown in Fig. 7.

\section{Measurements and computations}

First of all, it was necessary to run through the full range of supply voltage. This made it possible to define the range of changes in current and voltages for all circuit elements and find the supply voltage value where the ferroresonance 


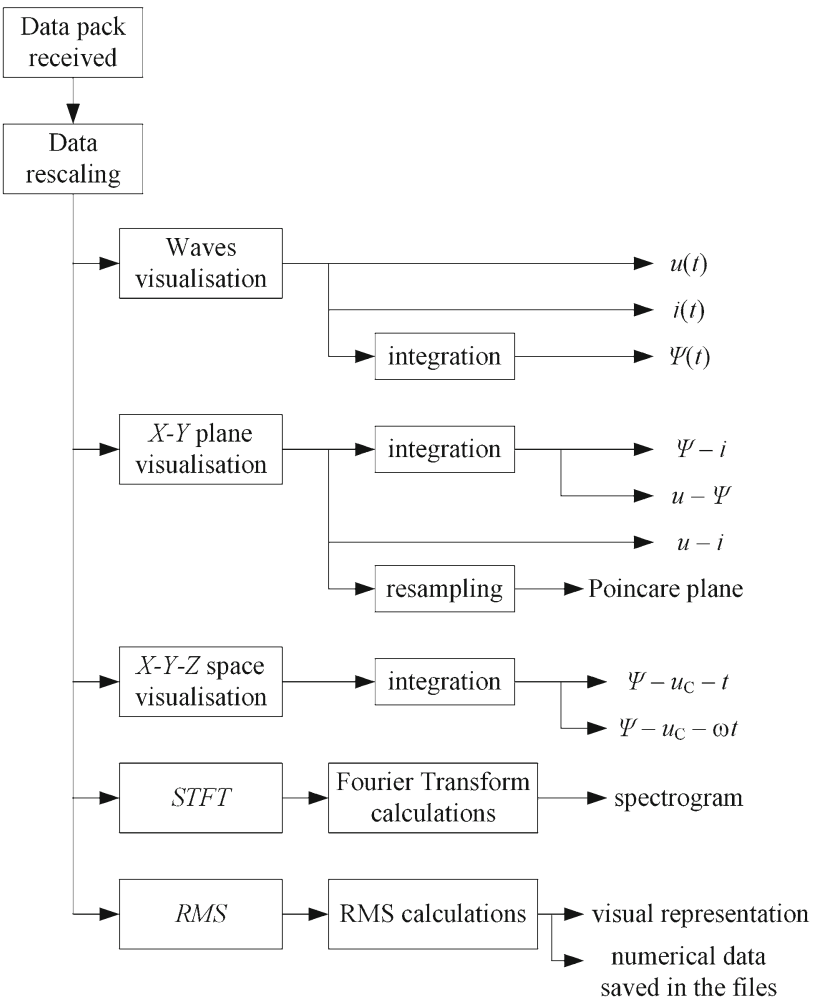

Fig. 7 Block diagram (process flowchart) of functionality and capabilities of original control program

Table 2 Maximum peak amplitude values of particular quantities obtained for all circuit elements

\begin{tabular}{lr}
\hline Supply voltage $e, \mathrm{~V}$ & 85 \\
Circuit current $i, \mathrm{~mA}$ & 42 \\
Capacitor voltage $u_{\mathrm{C}}, \mathrm{V}$ & 194 \\
Coil voltage $u_{\mathrm{L}}, \mathrm{V}$ & 184
\end{tabular}

occurs. Maximum values of particular quantities obtained for all circuit elements are given in Table 2.

The conducted measurements provided the information of voltage 'location' of the ferroresonance phenomenon. Ferroresonance occurs close to the supply voltage value corresponding to milliampere current circuit response.

A preview of the full range voltage-current circuit behavior made it possible to distinguish three circuit operating states: two steady states with different levels (low and high coil core saturation) and the transient state, when the ferroresonance occurs. Examples of three different circuit operating conditions are depicted in Fig 8.

\subsection{Characteristics of the test circuit signals (STFT analysis)}

Voltage-current signals measured and reviewed over a full supply voltage range have also been recorded. Recorded data were used to analyze the character of the signals, in particular in relation to frequency changes and harmonic distortions.

The traditional FFT analysis $[27,28]$ is used to obtain the characteristic frequencies present in the signals. This method allows us to examine the amount of distortion in the input signal by calculating the magnitude spectrum. The analysis of the signal has been divided into two different intervals. The voltage and current signals for each ferroresonance circuit steady state are shown alongside the corresponding magnitude spectrums in Fig. 9. One can observe that during the prolonged ferroresonance the voltage and current of two different ferroresonant circuit steady states have different magnitude spectrums.

The presence of more than one characteristic frequency shows the multiplicity in periodicity, commonly present in some ferroresonant states. On account of nonlinearities, which are both high and variable (variability is progressive), a standard harmonic analysis is insufficient. In such situations, in addition to information about what components are present in a given signal, the course of their variability over time is also important. Therefore, spectral analysis has been used.

There are many methods of the so-called time-frequency analysis, which allow to visualize the course of spectrum variability of signals over time. One of the basic ones is the so-called short time Fourier transform (STFT) [29-31]. It is founded upon the fact that the analysis window is shifted along the time axis, and after each shift the FFT signal inside the window is calculated. Depending on how the analysis parameters are selected (window width, step with which we move them and FFT parameters), different results are obtained. The amplitude spectrum resulting from this analysis is called a spectrogram, and it can be presented as a 3D or 2D graph. The 3D example for investigated circuit is shown in Fig. 10.

It is worth to mention that it is important to correctly set the FFT parameters as well as the signal sampling parameters to obtain a signal which is free of the FFT artifacts like aliasing, spectrum leakage and poor frequency resolution [32,33].

\subsection{True RMS value}

The root mean square mathematical operation is widely used in electrical engineering [34,35]. For this reason, the computing possibilities of the developed system were also tested in measuring the RMS values of the circuit quantities. According to [36], the RMS value of the periodic waveform is defined by the formula:

$$
F_{\mathrm{RMS}}=\sqrt{\frac{1}{T} \int_{0}^{T}(f(t))^{2} \mathrm{~d} t},
$$


Fig. 8 Examples of three different circuit operating conditions

Fig. 9 Current for all three discussed circuit states $(\mathbf{a}-\mathbf{c})$ and voltage (d); steady-state, high-saturation conditions; waveforms and results of FFT analyses
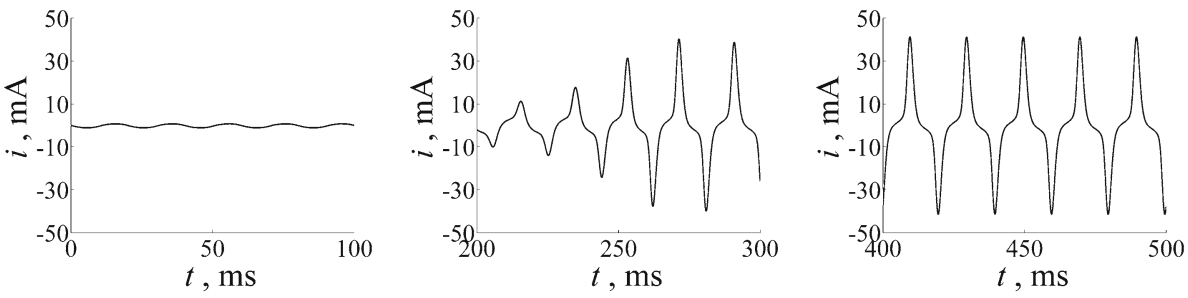

(a)
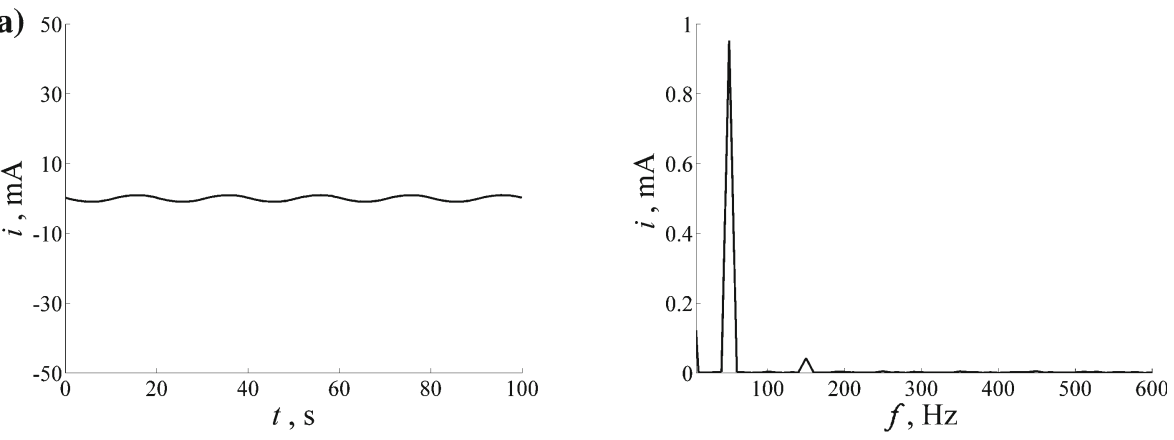

(b) 5
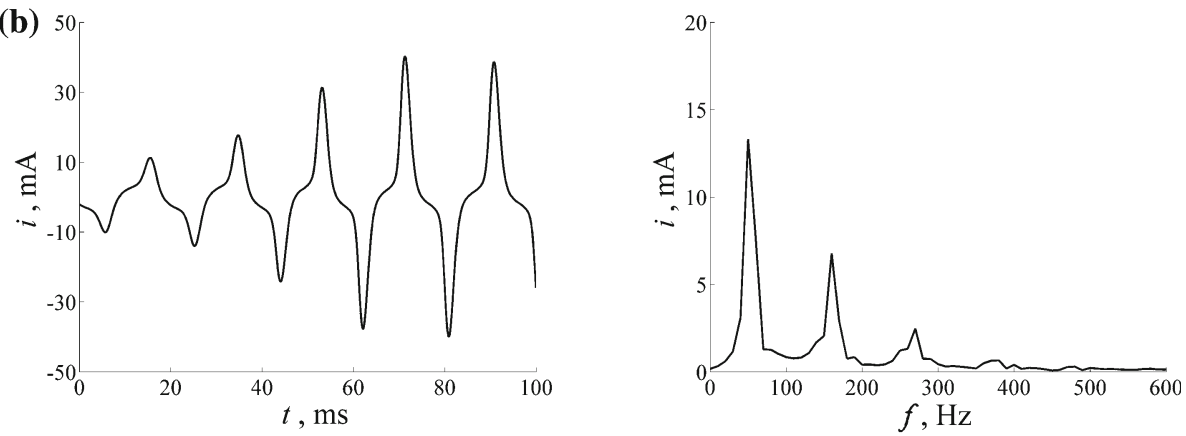

(c)
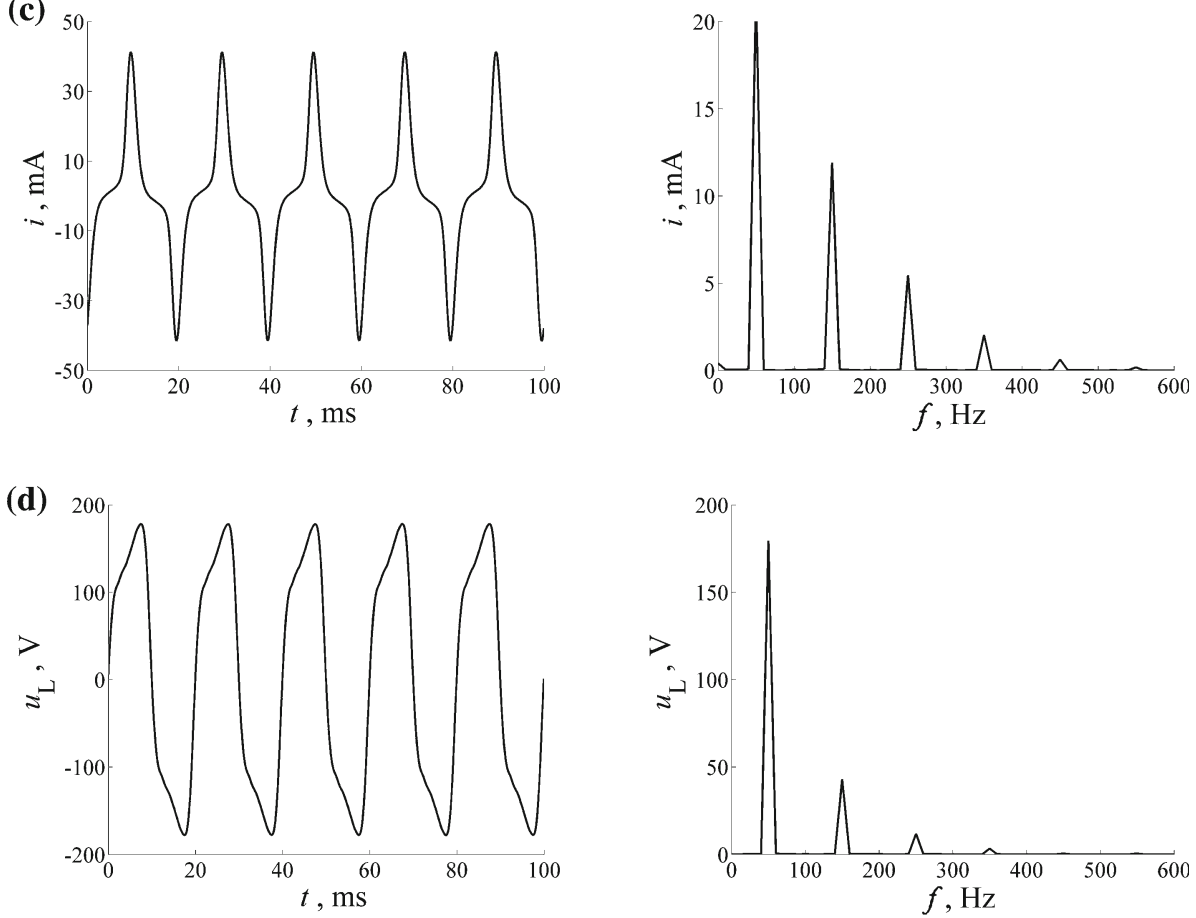


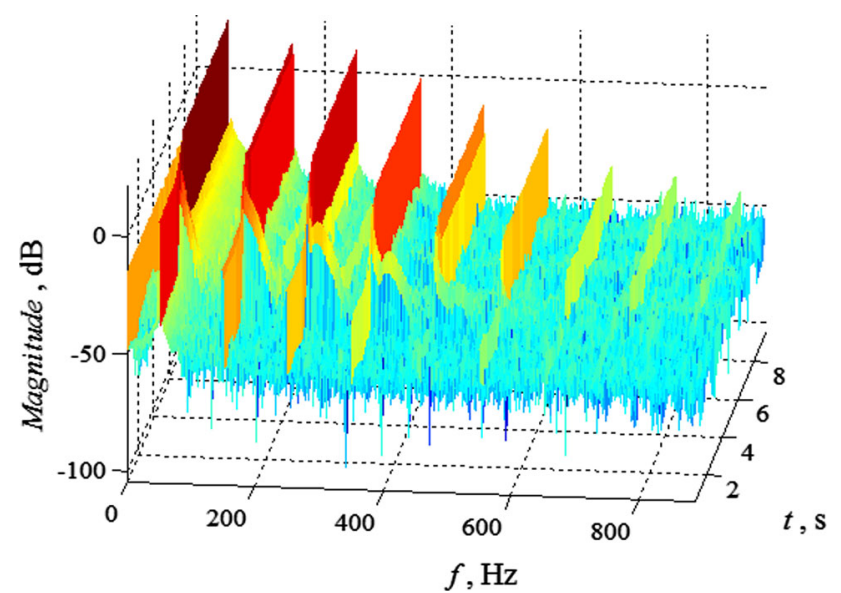

Fig. 10 3D example of spectrogram (time-frequency representation) for investigated circuit

where $F_{\mathrm{RMS}}$ is the RMS value, $T$ is the waveform period and $f(t)$ denotes instantaneous values of the waveform.

Computation results are shown in Fig. 11, and two waveforms: current and voltage, are demonstrated with corresponding RMS values.

The current and voltage waveforms recorded in the ferroresonance circuit, especially at the high saturation of the coil core, were strongly deformed (Fig. 9c, d).

Interesting result was obtained during analysis of the circuit in the steady state and with highly saturated coil core. Table 3 presents examples of measurement results; comparison of values measured with a universal multimeter with the 'True RMS' function and calculated by the developed measurement system (for the described high-saturation case). Due to the implementation of (1), the values calculated by Arduino should be recognized as identical with reference values (calculated according to the definition formula).

The following formula was used to calculate relative percentage errors for the values measured with the multimeter:

$\varepsilon=\frac{\left|X_{\mathrm{def}}-X\right|}{X_{\mathrm{def}}} \cdot 100 \%$,

Fig. 11 Examples of coil current (a) and voltage (b) waveforms together with corresponding RMS values
Table 3 Comparison of RMS values, example of results from two measurement devices: multimeter (a), Arduino-based system (b)

\begin{tabular}{llll}
\hline & & & Percentage error \\
Current $I, \mathrm{~mA}$ & Multimeter & 12.71 & 28.84 \\
& Arduino & 17.86 & Reference value \\
Coil voltage $U_{\mathrm{L}}, \mathrm{V}$ & Multimeter & 128.70 & 1.64 \\
& Arduino & 130.84 & Reference value \\
\hline
\end{tabular}

Errors are given for values measured with multimeter

where $\varepsilon$ is the relative error, $X_{\text {def }}$ is the RMS value calculated in accordance with definition (1), $X$ is the RMS value measured with the multimeter.

\subsection{Measurements and verification of capacitive reactance}

The acquisition of waveforms over full range of available supply voltage and accessibility of RMS/amplitude data at any time instant have made it possible to analyze character and behavior of different circuit elements. The developed system uses the current and voltage of capacitor waveforms to calculate its capacitive reactance. Capacitance values are easily extracted, assuming that the element operates as an ideal capacitor. A single time period is selected from the waveform and subjected to a quasi-steady-state analysis (Fig. 12). Then, through a simple FFT analysis, fundamental voltage and current harmonic amplitudes can be obtained (Fig. 13).

The capacitance is obtained through the well-known formula [36]:

$C=\frac{I_{(1 \mathrm{~h})}}{U_{(1 \mathrm{~h})} 2 \pi f}$

where $I$ and $U$ are, respectively, the current and voltage first time harmonic values and $f$ is supply voltage frequency (i.e., $50 \mathrm{~Hz})$.

Calculations have been conducted for two time intervals, with two different (low and high) coil saturations conditions; capacitance values have been obtained. These are: (a)

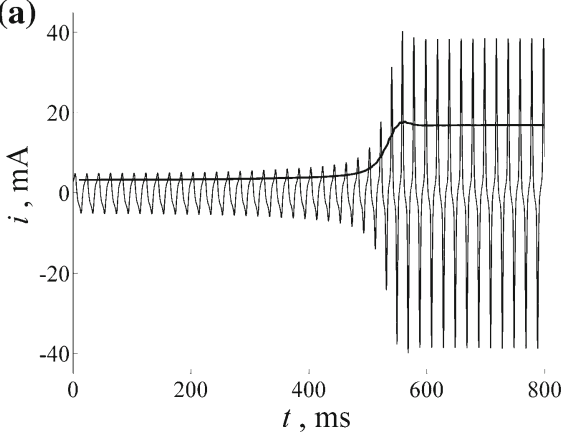

(b)

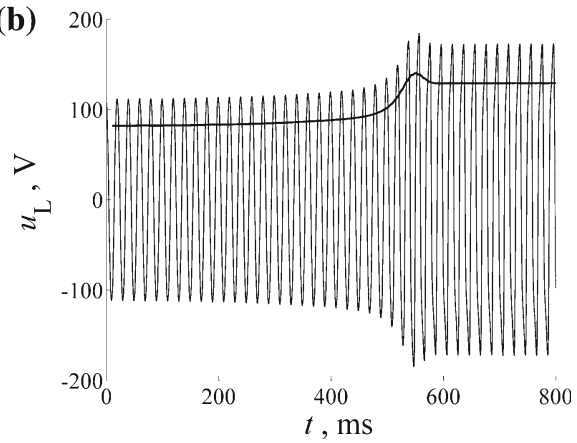




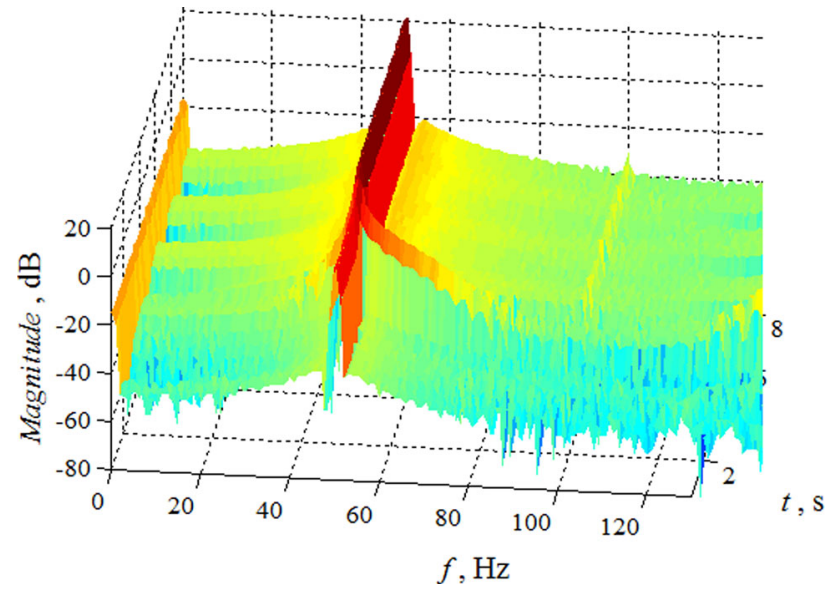

Fig. 12 The circuit current 3D spectrogram limited to the fundamental harmonic

$C=29 \mu \mathrm{F}$ (for low saturation condition) and $C=29.1 \mu \mathrm{F}$ (for high coil saturation).

\subsection{Computation of the nonlinear coil flux linkage}

The flux linkage is defined as a time integral of the voltage across the coil [37]:

$\Psi(t)=\int_{t_{0}}^{t} u_{L}(t) \mathrm{d} t+\Psi\left(t_{0}\right)$

Fig. 13 Extraction of the harmonic fundamental values from current and voltage waveforms; steady-state, high-saturation scenario
This quantity is not measurable using conventional engineering tools. However, it is required in order to perform the ferroresonance analysis.

In the FeD system, the flux linkage is obtained by means of numerical computations of the integral (4). The trapezoidal integration method is applied. Example of the obtained flux linkage is presented in Fig. 14 together with the investigated voltage waveform.

\subsection{Iron core coil examination}

To analyze the ferroresonance phenomenon, there is a need to model the nonlinear coil core characteristics. At first, previously recorded current waveform and the computed flux linkage waveforms have been used. This helped to plot hysteresis loops of the coil [37] (Fig. 15).

In many ferroresonance studies the nonlinear coil core is represented by a single magnetization curve [11,38-41], not taking into account a hysteresis phenomenon. Because of its complexity, the hysteresis itself is then approximated through a determination of the power losses $[42,43]$. The total core loss is represented by a constant resistance. In reality such a computed resistance value is not constant, but it decreases as saturation level goes up [44]. (This will be proved in the next subsection.)

In ferroresonance investigation, the shape of hysteresis curve significantly influences the ferroresonance phenomenon $[45,46]$. This is true not only for the major loop,

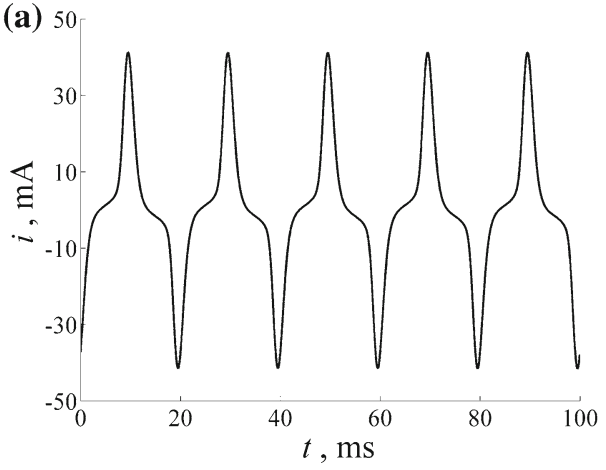

(b)

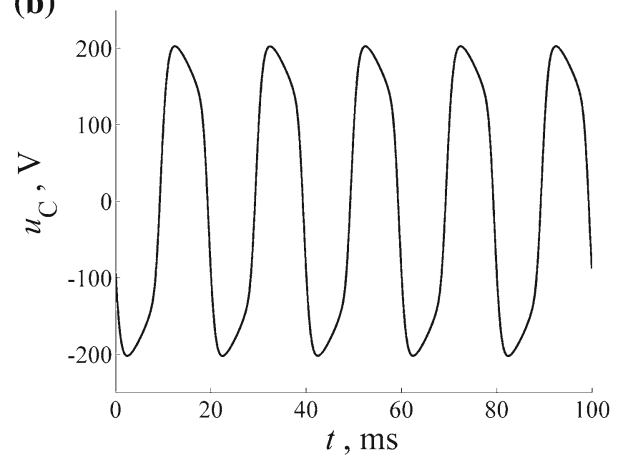

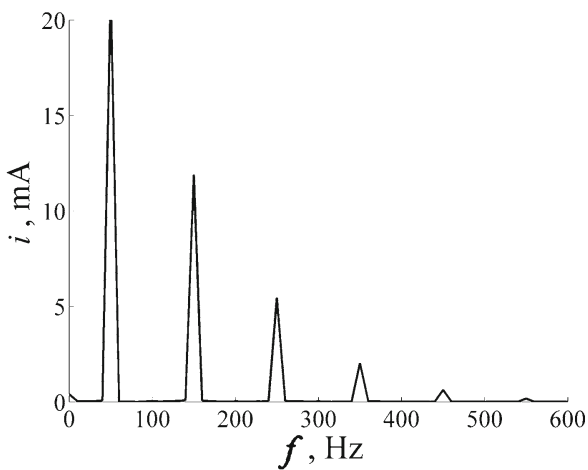

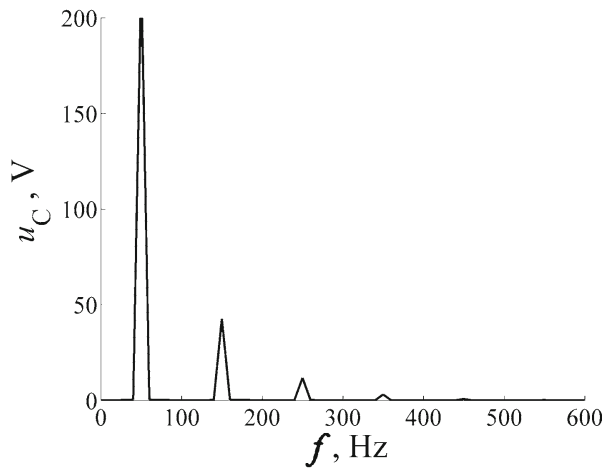


Fig. 14 Examples of the voltage (a) and magnetic flux (b) waveforms of nonlinear coil for a high saturation of the core; supply voltage waveform added for comparison in a (a) 200

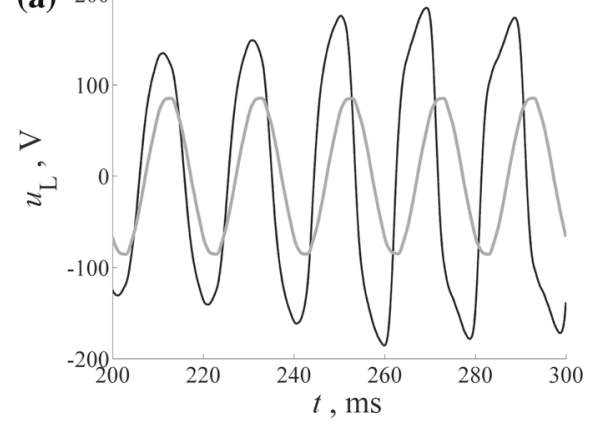

(b)

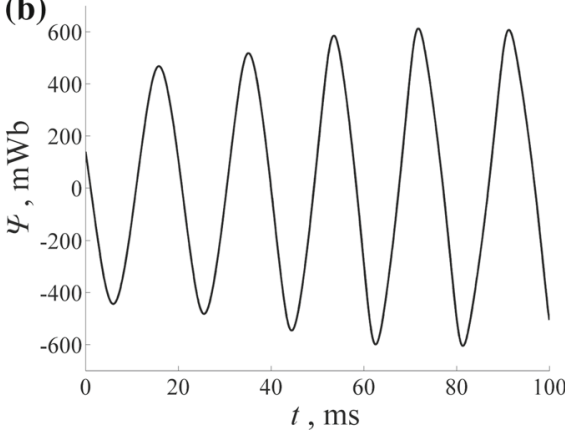

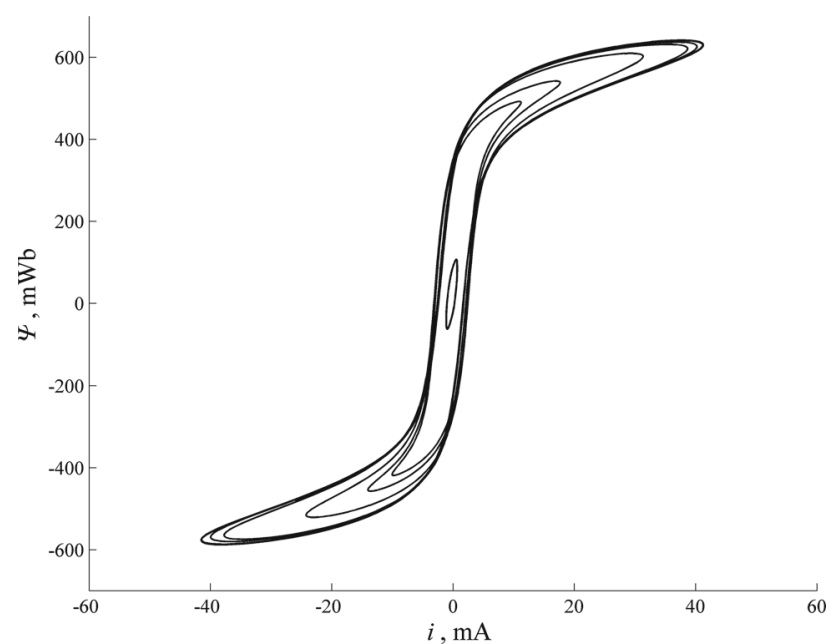

Fig. 15 Exemplary plot of flux linkage versus current (the hysteresis curves)

but also in relation to various minor loops [47]. These are often ignored, e.g., in many computational programs.

\subsection{Iron core coil loss classification}

The power loss in an iron core coil can be associated with several different properties and phenomena $[48,49]$ :

- resistance of the windings- 'copper loss',

- magnetic friction in the core-'hysteresis',

- electric currents induced in the core-'eddy currents',

- physical vibration and noise of the core and windings,

- electromagnetic radiation,

- dielectric loss in materials used to insulate the core and windings.

As opposed to all other losses, copper losses are present even if the winding current does not change. All other losses drop down to zero for DC excitation. Hysteresis and eddy current losses are collectively known as iron loss or core loss (even if a ferrite core is used).

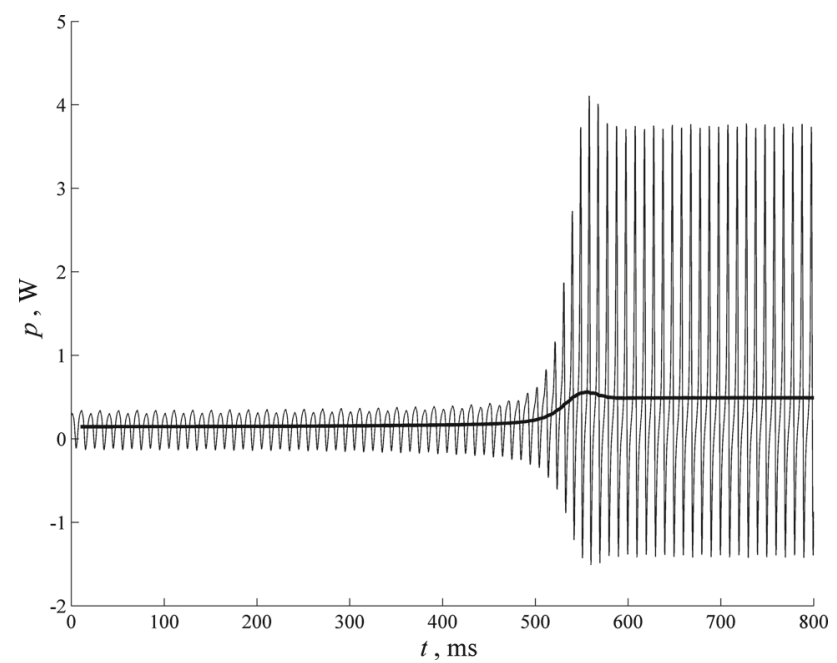

Fig. 16 The time functions of instantaneous power and active power of the iron core coil

No matter how they are interpreted the total losses can be obtained directly from the coil waveforms. The instantaneous power is the product of the coil terminal voltage and current:

$p(t)=u(t) \cdot i(t)$

Further analysis can be performed when computations of the active power are taken into account [36,50,51]:

$P=\frac{1}{T} \int_{t}^{t+T} p(t) \mathrm{d} t$

The above integral is computed numerically for every time instant $t=t_{\text {(now) }}$ in the FeD system [trapezoidal method is used for computing (4), as before]. The results are depicted in Fig. 16.

Determination of equivalent resistance parameter in two simple models of the nonlinear coil is possible, when active power value is available (Fig. 17).

Accessibility of active power at every time instant is necessary, when equivalent resistance values in the described models are calculated. 
(a)

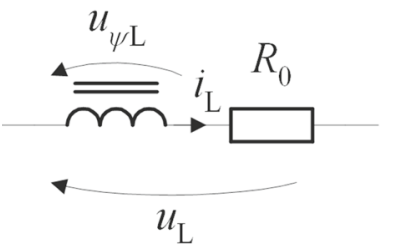

Fig. 17 Simple nonlinear coil models: series (a) and parallel (b)

The developed system provides a full access to the visualization of the waveforms. An example of how the equivalent resistance values vary in time (in the case of both models) is shown in Fig. 18.

Obtained core losses and characteristics $\psi(i)$ and $u_{R_{\mathrm{L}}}(i)$ will be used in future studies for making improvements to the nonlinear coil models.

\section{Analysis of ferroresonance}

There are several tools available to study the nonlinear dynamic systems [52-55]. Some of them are based on bifurcation theory [56-59]. This theory examines the evolution of the system solution by changing the value of a control parameter. However, in this paper the ferroresonant circuit is analyzed differently, using diagnostic methods. In the diagnostic approach the ferroresonance can be characterized by using either a spectral study method based on Fourier's analysis or a stroboscopic analysis based on Poincaré maps [60-62]. These can be used to differentiate between ferroresonance states (e.g., a quasi-periodic state from a chaotic state).

A dynamical, nonautonomous system can be described through the following system of differential state equations $[58,63]$ :

$\left\{\begin{aligned} \frac{\mathrm{d} x_{1}}{\mathrm{~d} t} & =f_{1}\left(x_{1}, x_{2}, \ldots x_{N}, t\right) \\ \frac{\mathrm{d} x_{2}}{\mathrm{~d} t} & =f_{2}\left(x_{1}, x_{2}, \ldots x_{N}, t\right) \\ \cdots & \\ \frac{\mathrm{d} x_{N}}{\mathrm{~d} t} & =f_{N}\left(x_{1}, x_{2}, \ldots x_{N}, t\right)\end{aligned}\right.$

Fig. 18 Examples of time variation of equivalent resistance values for series (a) and parallel (b) model and changes of this variation as the function of circuit current as well as supply and coil voltage

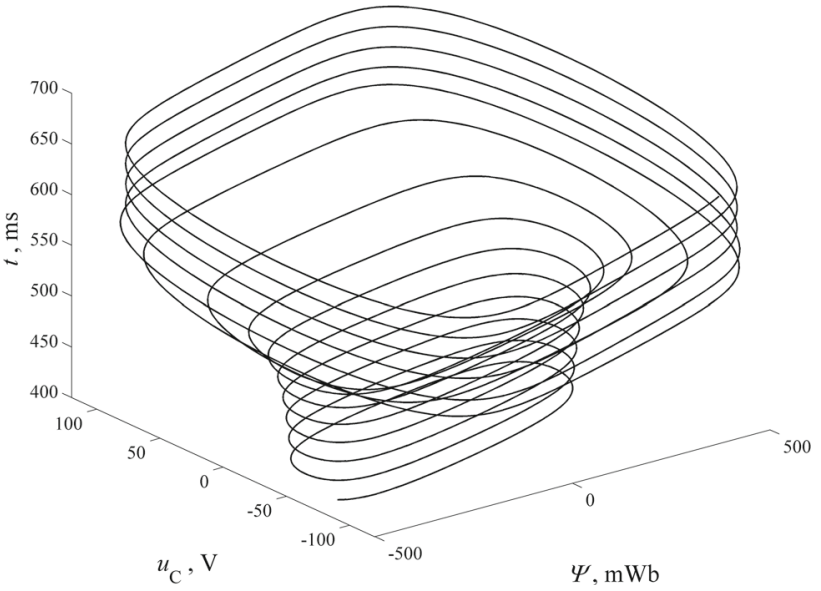

Fig. 19 Example of phase trajectory of the investigated system

In terms of discussed ferroresonance circuit, the following sets of equations depending on assumed mathematical model of nonlinear coil may be formulated:

$\left\{\begin{array}{c}\frac{\mathrm{d} \Psi}{\mathrm{d} t}=f_{1}\left(\Psi, u_{\mathrm{C}}, t\right) \\ \frac{\mathrm{d} u_{\mathrm{C}}}{\mathrm{d} t}=f_{2}\left(\Psi, u_{\mathrm{C}}, t\right)\end{array}\right.$

Therefore, two separate cases can be found, where accordingly $u_{\mathrm{C}}$ and $\Psi$ or $i_{\mathrm{L}}$ are state variables.

State space is an illustration of time development of state variables $[64,65]$. Due to the fact that the investigated system is nonautonomous, three-dimensional space is necessary. System of equations related to the model can be also modified to fit to the following form:

$\left\{\begin{array}{l}\frac{\mathrm{d} x_{1}}{\mathrm{~d} t}=f_{1}\left(x_{1}, x_{2}, x_{3}\right) \\ \frac{\mathrm{d} x_{2}}{\mathrm{~d} t}=f_{2}\left(x_{1}, x_{2}, x_{3}\right) \\ \frac{\mathrm{d} x_{3}}{\mathrm{~d} t}=1\end{array}\right.$

Phase trajectory displaying two examples of steady states and transient state between them is presented in Fig. 19.

In order to reduce dimensionality of information about changes of state variables, it is possible to project the whole three-dimensional trajectory onto a horizontal plane. This (a) 50

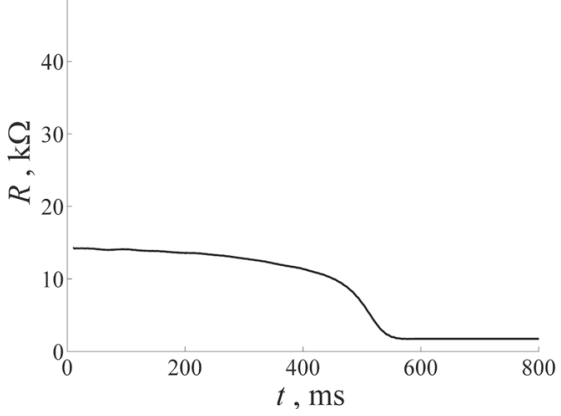

(b) 50

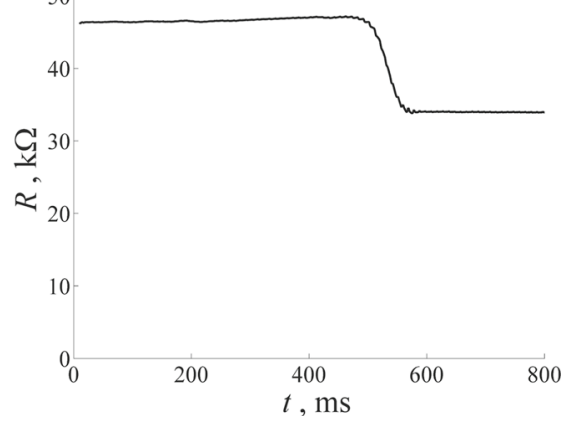




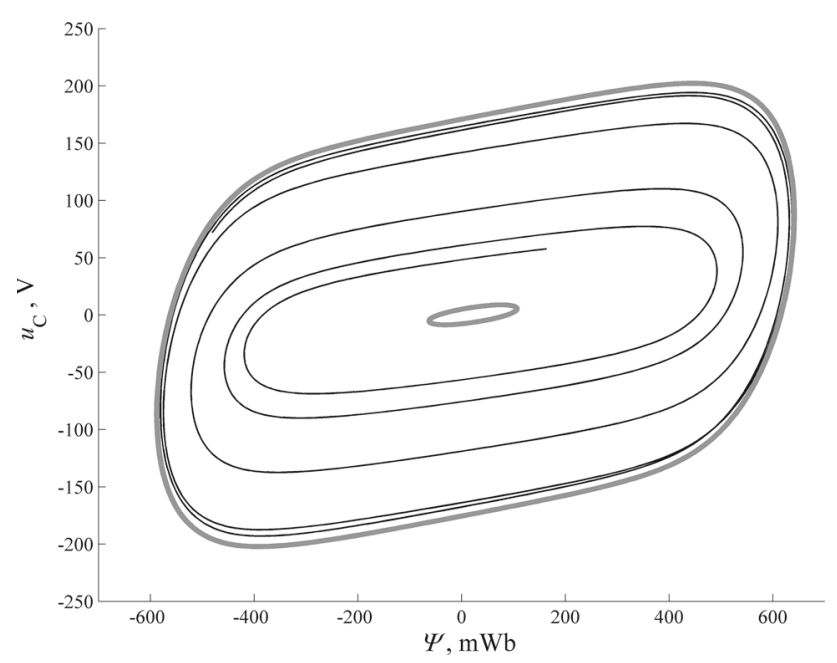

Fig. 20 Phase plane of the investigated system obtained from phase space presented in Fig. 19; bold line marks the steady-state circuit condition for low and high saturation of the coil core, respectively

operation results in obtaining a state plane of the system as depicted in Fig. 20.

Due to the presence of a periodic input in the discussed system, a three-dimensional representation can be produced. This corresponds to a trajectory generated through a rotating $\psi_{\mathrm{r}}-u_{\mathrm{C}}$ plane (Fig. 21), with:

$\psi_{\mathrm{r}}=\psi+\psi_{\mathrm{ref}}$,

where $\psi_{\text {ref }}$ is an arbitrary value added, since $\psi_{\mathrm{r}}$ should also be positive.

Figure 21 not only hints at the existence of steady states but also shows the effect of deformation of the waveforms of the state variables. Poincare map may be obtained through the intersection of a trajectory with a plane at a single angle $\omega \mathrm{T}$ (Fig. 22).

A record of the intersection points from all time instants of trajectory results is expressed by the phase plane (Fig. 23).

The above analysis can be performed also for a dynamical condition of the system. The system trajectory on the rotating $\psi_{\mathrm{r}}-u_{\mathrm{C}}$ plane for an example of a transient state is presented in Fig. 24.

A Poincaré map related to the presented dynamical trajectory is presented in Fig. 25.

In case of transient state the phase plane derived from Poincare maps can also be obtained (Fig. 26), in a manner similar to that used for steady states.

The above analysis is implemented in the FeD system. The instant values of the measured and calculated values are recorded, leading to the generation of the Poincaré map. The $2 \mathrm{D}$ visualization can be then easily interpreted by the user.

\section{Simulation module}

The FeD diagnostic system has been equipped with a simulation module used to model the nonlinear core coil. After a literature survey of many possible alternatives (as given in [66-68]) and basing on authors' personal experiences (various studies $[9,10,17,18]$ ), a fractional calculus model of the ferromagnetic coil has been chosen. From the field of fractional calculus, the Caputo fractional derivative is applied [69,70]:

${ }_{t_{0}}^{\mathrm{C}} \mathrm{D}_{t}^{\alpha} f(t)=\frac{1}{0(1-\alpha)} \int_{t_{0}}^{t} \frac{f^{(1)}(\tau)}{(t-\tau)^{\alpha}} \mathrm{d} \tau$

where only the range of $\alpha \in[0,1]$ is considered.

Fractional derivatives have been applied with success in circuit analyses in modeling supercapacitors [71-74] and (important for this study) ferromagnetic core coils [9,75-77]. Model containing a nonlinear fractional coil and a resistance connected in parallel (Fig. 27) has been used in this study.

The nonlinear fractional coil is defined by the fractional differential equation:

${ }_{t_{0}}^{\mathrm{C}} \mathrm{D}_{t}^{\alpha} \Psi=u_{\mathrm{L}}$

with $\Psi$ being an artificial variable with the unit $\mathrm{Wb} \mathrm{s}^{(\alpha-1)}$ and a nonlinear function $\Psi(i)$. The nonlinear function is defined by $(i, \Psi)$ value pairs, where the $i$ values are set as 15 values ranging from 0 to $42 \mathrm{~mA}$ and the $\Psi$ values are estimated. Both the fractional coil and resistance have a different effect on the shape of a resulting hysteresis curve. Estimation of model parameters is possible in FeD system. The obtained values are given in Table 4 .

A comparison of the simulated hysteresis curve and the one obtained from measurements is presented in Fig. 28, while a comparison of the current waveforms is presented in Fig. 29.

In order to judge the accuracy of the results, the current waveforms have been compared. The following error formula was used:

$\varepsilon=\sqrt{\sum_{i=1}^{n}\left(f_{i(\mathrm{~m})}-f_{i(\mathrm{~s})}\right)^{2}} \frac{100}{n F_{\max }}$

where $f_{i(\mathrm{~m})}, f_{i(\mathrm{~s})}$ voltage or current value for the $i$ th time instance, $F_{\max }$ maximum value of the respective waveform. The index $m$ denotes measured values, while $s$ denotes those obtained by simulations. For the presented current waveforms, the computed value is $\varepsilon=0.04 \%$.

In future investigations, the model can be studied from the viewpoint of its dynamic behavior, as this is important for ferroresonance analyses $[10,47]$. However, because of the 
Fig. 21 Three-dimensional representation of trajectory generated through the rotating $\psi_{\mathrm{r}}-u_{\mathrm{C}}$ plane for two different saturation conditions of the ferromagnetic core coil: low saturation (a), high saturation (b) (a)

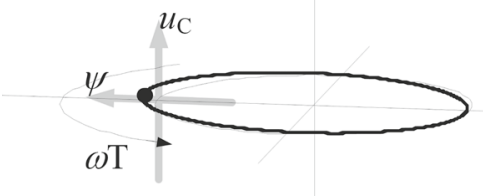

(a)

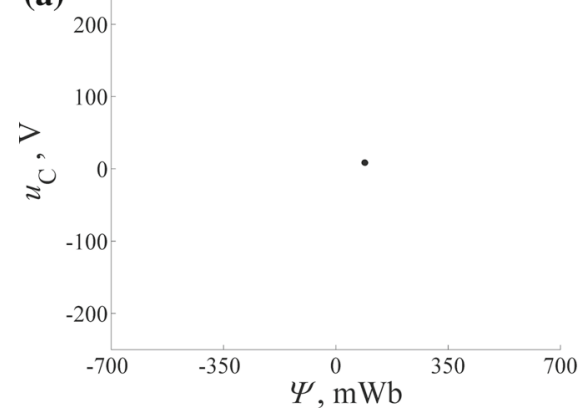

(b)

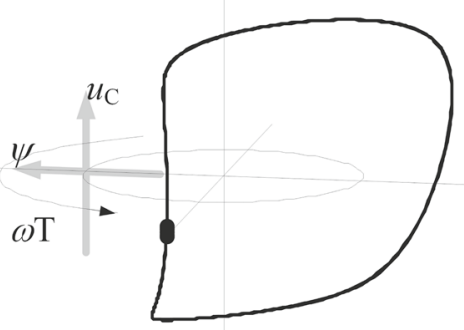

(b)

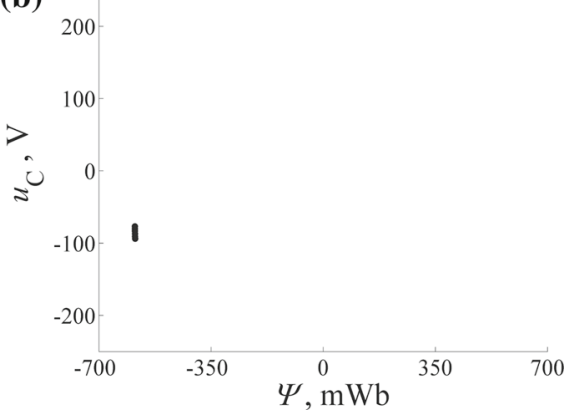

Fig. 22 Poincare maps of the system trajectory presented in Fig. 21-low saturation (a) and high saturation (b)

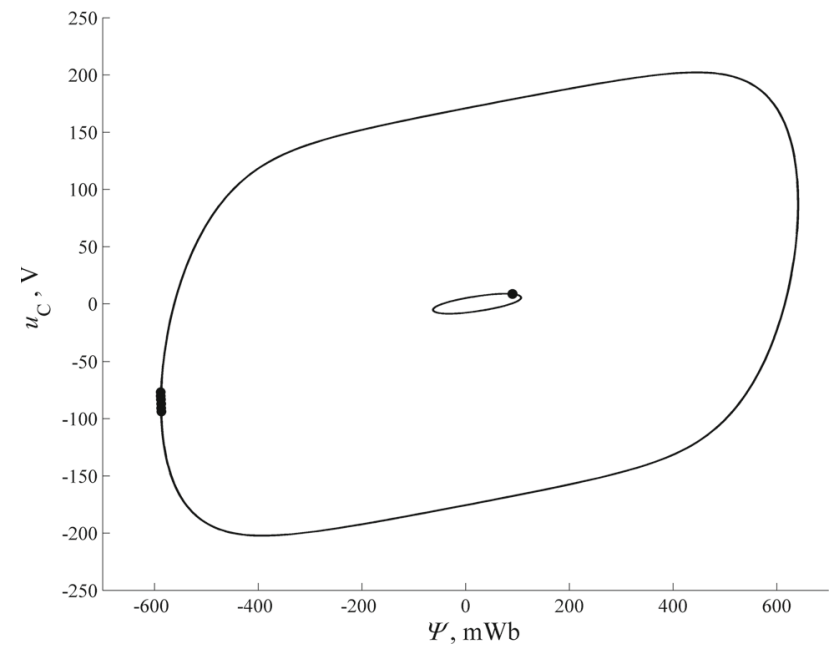

Fig. 23 Intersection points from Fig. 22 shown on a phase plane with the steady state for two analyzed saturation conditions of the coil core

complexity of such problems (fractional differential equation and nonlinear function), this requires numerical methods (e.g., as given in [81-83]).

\section{Conclusions}

System for measurements and diagnostics of ferroresonant circuits has been developed. It has been called FeD.

The initial part of the system is aimed at a series of signal transformations (Fig. 3 in Sect. 3). The processed signal is then sent to the Arduino module.

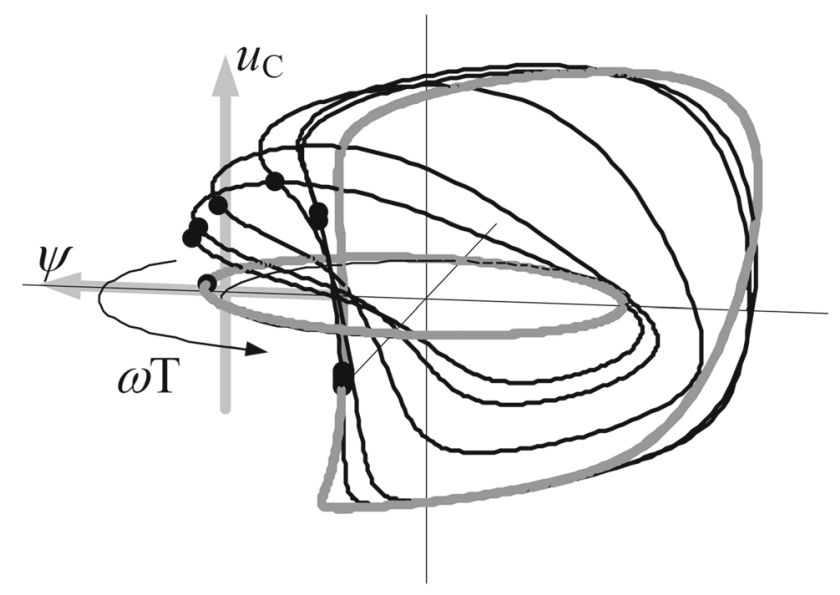

Fig. 24 Three-dimensional representation of trajectory generated through the rotating $\psi_{\mathrm{r}}-u_{\mathrm{C}}$ plane for an example of a transient state; bold line marks the steady-state trajectories for low- and high-saturation conditions of the coil core

The Arduino module makes it possible to perform some single signal operations in online mode (e.g., RMS value calculation).

A unique feature of Fed system is original software developed by the authors. The program allows for a cooperation between the Arduino module and a PC, i.e., sending commands for measurements and data transfer.

The functionality of the program has been implemented specifically for the studies of a ferroresonant circuit. The following functions are present: 


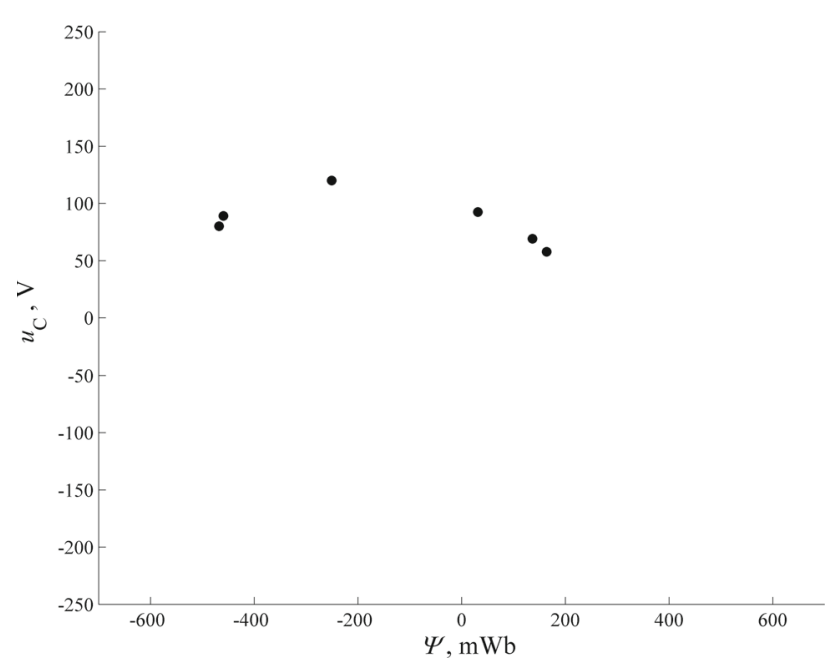

Fig. 25 Example of Poincare map for the trajectory presented in Fig. 24

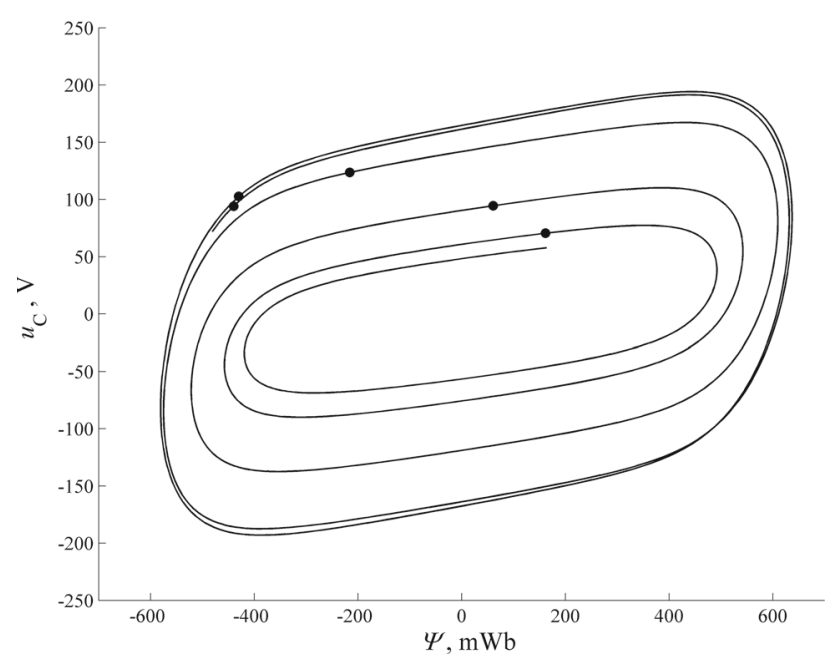

Fig. 26 The Poincaré map (dots) and phase plane (solid line) of the studied system (transient state)

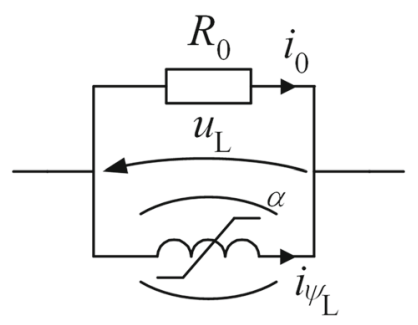

Fig. 27 Applied ferromagnetic core coil model (the fractional order element is marked with a symbol introduced in $[78,79]$ )

- preview of the voltage and current waveforms,

- True RMS measurements (and their visualizations),

- computations of quantities that are not measured directly (e.g., flux, power losses),

- advanced signal processing analyses, e.g., STFT (Sect. 5.1),
Table 4 Estimated model parameter values

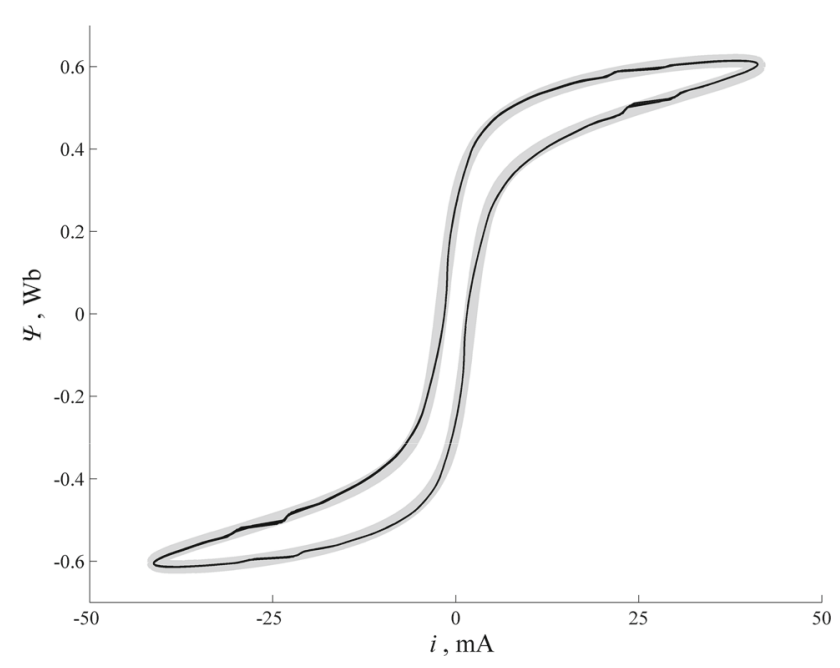

Fig. 28 Comparison of simulated and measured hysteresis curve (measurement results marked in gray)

- advanced ferroresonance analyses (Poincare maps, 3D trajectory visualizations-Sect. 6).

The FeD system has been equipped with a simulation module. The simulations are related to ferroresonant circuit, and a full description of circuit elements is required. For the ferromagnetic coil, a nonlinear fractional model is used. The capacitor is assumed to be a linear element. The module allows for an estimation of the parameters of each of these elements basing on their voltage and current waveform measurements.

To summarize, FeD system is equipped with a full range of functionality ranging from basics like previews of measured current and voltage waveforms to advanced analyses of a ferroresonant circuit. Each studied circuit provides 


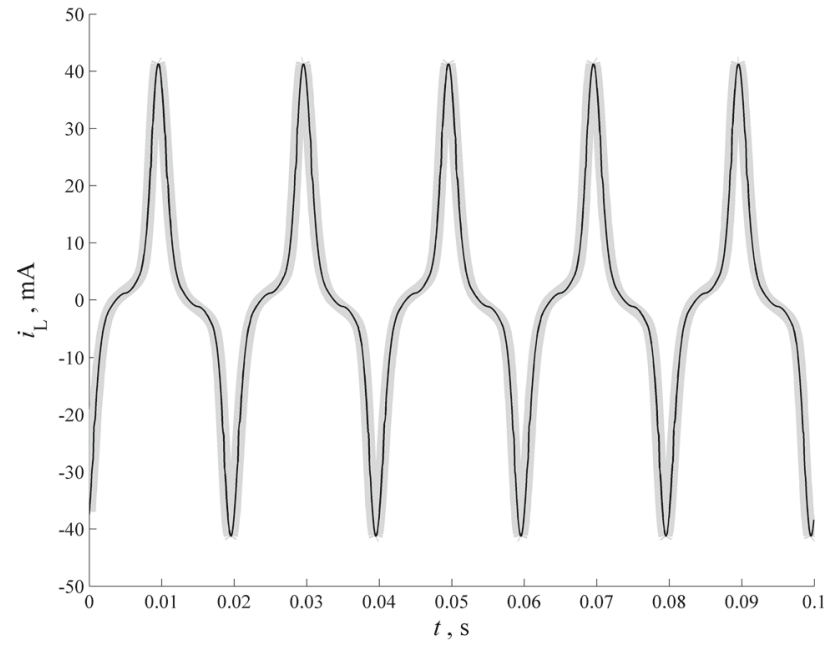

Fig. 29 Comparison of simulated and measured current waveforms (measurement results marked in gray)

unique $u-i$ waveforms determined by individual properties of its elements (e.g., distinctive material properties of the iron core coil). For these waveforms, the FeD system performs a complete diagnostics, which yields a full spectrum of individual quantities and information on the behavior of circuit elements (e.g., magnetic hysteresis loop). The acquired features of the circuit and its components determine the approach for the analysis of the ferroresonance phenomenon and the manner in which the nonlinear coil is modeled.

Possibilities and needs for further research include:

- the application of the FeD system and its algorithms for investigation of different types of ferroresonance modes, e.g., subharmonic and quasi-periodic modes; in this study, intentionally - only the fundamental mode was taken into account because of its predictability and deterministic behavior,

- with an increase of the ferromagnetic core saturation level, the resistance decreases (what has been proven in Sect. 5.6); the obtained resistance data will be used for study of various ferromagnetic core coil models so that an optimal one can be selected (reflecting this behavior),

- incorporation of simulations of dynamic behaviors of ferroresonant circuits (including cases where ferromagnetic core coils are modeled with the usage of fractional derivatives); this requires the implementation of specific solvers (e.g., there are ones basing on various numerical methods for fractional differential equations like the SubIval numerical method [80-82] and others $[83,84]$.
Open Access This article is distributed under the terms of the Creative Commons Attribution 4.0 International License (http://creativecomm ons.org/licenses/by/4.0/), which permits unrestricted use, distribution, and reproduction in any medium, provided you give appropriate credit to the original author(s) and the source, provide a link to the Creative Commons license, and indicate if changes were made.

\section{References}

1. Valverde V, Mazon AJ, Zamora I, Buigues G (2011) Ferroresonance in voltage transformers: analysis and simulations. Renew Energy Power Qual J 1(10):465-471

2. Ferracci P (1998) Schneider-electric technical book, vol 190. Schneiders Group Technical collection

3. Valverde V, Buigues G, Mazón AJ, Zamora I, Albizu I (2012) Ferroresonant configurations in power systems. In: International conference on renewable energies and power quality (ICREPQ12), REandPQJ, Santiago de Compostela, Spain, vol 1, no 10, pp 474479

4. Jacobson DAN (2003) Examples of ferroresonance in a high voltage power system. In: Power engineering society general meeting. IEEE

5. Milicevic K, Vinko D, Vulin D (2014) Experimental investigation of impact of remnant flux on the ferroresonance initiation. Electr Power Energy Syst 61:346-354

6. Milicevic K, Emin Z (2009) Impact of initial conditions on the initiation of ferroresonance. Electr Power Energy Syst 31(4):146152

7. Iravani MR, Chaudhary AKS, Giesbrecht WJ, Hassan IE, Keri AJF, Lee KC, Martinez JA, Morched AS, Mork BA, Parniani M, Sharshar A, Shirmohammadi D, Walling RA, Woodford DA (2000) IEEE working group on modeling and analysis of systems transients, modeling and analysis guidelines for slow transients part III: the study of ferroresonance. IEEE Trans Power Deliv 15(1):255265

8. Arroyo A, Martinez R, Manana M, Pigazo A, Minguez R (2019) Detection of ferroresonance occurrence in inductive voltage transformers through vibration analysis. Electr Power Energy Syst 106:294-300

9. Majka $Ł$ (2019) Fractional derivative approach in modeling of a nonlinear coil for ferroresonance analyses. In: Ostalczyk P, Sankowski D, Nowakowski J (eds) 9th international conference on non-integer order calculus and its applications, Łódź, Poland. Springer, Cham, pp 135-147

10. Majka $Ł$ (2018) Applying a fractional coil model for power system ferroresonance analysis. Bull Pol Acad Tech Sci 66(4):467-474

11. Corea-Araujo JA, Guerra GJ, Martinez-Velasco A, GonzalezMolina F (2017) Generation of bifurcation diagrams for ferroresonance characterization using parallel computing. Balkan J Electr Comput Eng 5(2):77-85

12. Yang M, Sima W, Duan P, Zou M, Peng D, Yang Q, Duan Q (2017) Electromagnetic transient study on flexible control processes of ferroresonance. Electr Power Energy Syst 93:194-203

13. Di Mauro GF, Ferreyra R, Suárez JA, Jurado AD (2015) Overvoltage by ferroresonance on a rural distribution feeder: case report and simulation. Inge CUC 11:34-47

14. Tugai I (2015) Investigation of ferroresonance in electrical networks at open-phase operating conditions. Comput Probl Electr Eng 5(1):61-64

15. Valverde V, Mazón J, Buigues G, Zamora I (2012) Ferroresonance suppression in voltage transformers. Przegląd Elektrotechniczny 88(1):137-140 
16. Bakar AHA, Rahim NA, Zambri MKM (2011) Analysis of lightning-caused ferroresonance in Capacitor Voltage Transformer (CVT). Electr Power Energy Syst 33(9):1536-1541

17. Majka $€$ (2016) Measurement verification of the nonlinear coil models. In: Proceedings of the 39th international conference ICSPETO, Ustroń, vol 8990

18. Majka $€$ (2015) Measurement based inductor modeling for the purpose of ferroresonance analyses. In: Proceedings of the international conference AMTEE, Trebic, Czech Republic, vol 3

19. Bauer W, Kawala-Janik AD (2017) Implementation of bi-fractional filtering on the Arduino Uno Hardware Platform. Theory and applications of non-integer order systems: 8th conference on non-integer order calculus and its applications. Zakopane, Poland, pp 419-428

20. Klimas M, Majka $€$ (2018) Testing Arduino platform for ferroresonance circuit measurements. XLI Konferencja z Podstaw Elektrotechniki i Teorii Obwodw. In: Holajn P, Sztymelski K, Wegiera $\mathrm{G}$ (eds) 41st conference on fundamentals of electrotechnics and circuit theory. SPETO 2018. Gliwice: [Instytut Elektrotechniki i Informatyki Politechniki Śląskiej], Gliwice - Ustroń, pp 77-78

21. http://www.kared.com.pl/Products/11/48/Cyfrowy-rejestratorzaklocen-RZ-1.html. Accessed Feb 2019

22. Buła D, Lewandowski M (2018) Steady state simulation of a distributed power supplying system using a simple hybrid timefrequency model. Appl Math Comput 319:195-202

23. Grabowski D, Cristalli C (2015) Production line quality control using infrared imaging. Infrared Phys Technol 71:416-423

24. Paszek S, Nocon A (2015) Parameter polyoptimization of PSS2A power system stabilizers operating in a multi-machine power system including the uncertainty of model parameters. Appl Math Comput 267:750-757

25. Jurkojć J, Wodarski P, Michnik R, Bieniek A, Gzik M, Granek A (2017) The Standard Deviation of Differential Index as an innovation diagnostic tool based on kinematic parameters for objective assessment of a upper limb motion pathology. Acta Bioeng Biomech 19(4):77-87

26. Szczegielniak T, Piatek Z, Baron B, Jabłoński P, Kusiak D, Pasierbek A (2016) A discrete numerical method for magnetic field determination in three-phase busbars of a rectangular cross-section. Turk J Electr Eng Comput Sci 24(3):1279-1291

27. Jurkoj J (2018) Balance disturbances coefficient as a new value to assess ability to maintain balance on the basis of FFT curves. Acta Bioeng Biomech 20(1):143-151

28. Słania J, Ślązak B, Fidali M, (2014) Application of fast Fourier transform (FFT) in the analysis of a welding current instantaneous values waveforms during welding with a covered electrode. Arch Metall Mater 59(2):569-573

29. Kahankova R, Jaros R, Martinek R, Jezewski J, Wen H, Jezewski M, Kawala-Janik A (2017) Non-adaptive methods of fetal ECG signal processing. Adv Electr Electron Eng 15:476-490

30. Konieczny Ł, Burdzik R, Śleziak B (2009) Usage short time fourier transform in identification of vehicle shock absorber technical conditions researched by force vibration method. Probl Transp 4(3):71-77

31. Grabowski D, Walczak J, (2004) Neural approach to timefrequency signal decomposition. In: Rutkowski L, Siekmann JH, Tadeusiewicz R, Zadeh LA (eds) Artificial intelligence and soft computing. ICAISC, (2004) Lecture notes in computer science, vol 3070. Springer, Berlin

32. Lewandowski M, Walczak J (2018) Optimal base frequency estimation of an electrical signal based on Prony's estimator and a FIR filter. Appl Math Comput 319:551-561

33. Lewandowski M, Walczak J (2014) Current spectrum estimation using Pronys estimator and coherent resampling. COMPEL Int J Comput Math Electr Electron Eng 33(3):989-997

34. Gilmore J, Islam M, Duncan J, Natu R, Martinez-Duarte R (2017) Assessing the importance of the root mean square (RMS) value of different waveforms to determine the strength of a dielectrophoresis trapping force. Electrophoresis 38(20):2561-2564

35. Kampik M (2013) Analysis of the effect of DAC resolution on RMS value of the signal generated by the digital source of lowfrequency standard AC voltage. In: Proceedings of 2013 IEEE international instrumentation and measurement technology conference, Minneapolis. IEEE Press, Piscataway, pp 162-165

36. Akagi H, Watanabe EH, Aredes M (2017) Instantaneous power theory and applications to power conditioning, 2nd edn. Wiley, New York

37. Lacerda Ribas J, Lourenço EM, Leite J, Batistela N (2013) Modeling ferroresonance phenomena with a flux-current Jiles-Atherton hysteresis approach. IEEE Trans Magn 49(5):1797-1800

38. Radmanesh H (2012) Ferroresonance elimination in 275 kV substation. Electr Electron Eng 2(2):54-59

39. Emin Z, Tong YK (2001) Ferroresonance experience in UK: simulations and measurements. In: International conference on power systems transients (IPST), Rio de Janeiro, Brazil, pp 24-28

40. Jacobson DA, Menzies RW (2001) Investigation of station service transformer ferroresonance in manitoba hydro's 230-kV dorsey converter station. In: International conference on power systems transients (IPST), Rio de Janeiro, Brazil, p 2428

41. Janssens N, Vandestockt V, Denoel H, Monfils PA (1990) Elimination of temporary overvoltages due to ferroresonance of voltage transformers: design and testing of a damping system. In: Proceedings of CIGRE, paper pp 33-204, 18

42. Radmanesh H, Rostami M, Khalilpour J (2012) Ferroresonance in voltage transformer considering linear and nonlinear core losses effect. Int J Comput Electr Eng 4(5):789-793

43. Javora R, Iwahara M, Yamada S (2005) Effect of dynamic core losses on ferroresonance phenomena. J Mater Process Technol 161(1-2):156-161

44. Rezaei-Zare A, Iravani R, Sanaye-Pasand M, Mohseni H, Farhangi S (2008) An accurate hysteresis model for ferroresonance analysis of a transformer. 2008 IEEE power and energy society general meeting: conversion and delivery of electrical energy in the $21 \mathrm{st}$ century. Pittsburgh, PA, pp 1-1

45. Rezaei-Zare A, Iravani R, Sanaye-Pasand M (2009) Impacts of transformer core hysteresis formation on stability domain of ferroresonance modes. IEEE Trans Power Deliv 24(1):177-186

46. Patel B, Das S, Roy CK, Roy M (2008) Simulation of ferroresonance with hysteresis model of transformer at no-load measured in laboratory. TENCON 2008, IEEE region 10 conference, Hyderabad, pp 1-6

47. Chwastek K, Baghel APS, Sai Ram B, Borowik B, Daniel L, Kulkarni SV (2018) On some approaches to model reversible magnetization processes. J Phys D Appl Phys 51(14):1361-6463

48. Aydina P, Rasiloab F, Martina A, Belahcena L, Danielc A, Haavistoa A, Arkkioa A (2019) Effect of multi-axial stress on iron losses of electrical steel sheets. J Magn Magn Mater 469(1):19-27

49. Zirka SE, Moroz YI, Harrison RG, Chwastek K (2012) On physical aspects of the Jiles-Atherton hysteresis models. J Appl Phys 112(4):043916

50. Grady WM, Santoso S (2012) Understanding power system harmonics. University of Texas at Austin, Department of Electrical and Computer Engineering

51. Grabowski D, Maciążek M, Pasko M, (2013) Sizing of active power filters using some optimization strategies. COMPEL 32(4):13261336

52. Chakravarthy SK, Nayar CV (1995) Series ferroresonance in power systems. Electr Power Energy Syst 17(4):267-274

53. Mork BA, Stuehm DL (1994) Application of nonlinear dynamics and chaos to ferroresonance in distribution systems. IEEE Trans Power Deliv 9(2):1009-1017

54. Araujo AEA, Soudack AC, Marti JR (1993) Ferroresonance in power systems: chaotic behaviour. IEE Proc C 140(3):237-240 
55. Kieny C (1991) Application of the bifurcation theory in studying and understanding the global behavior of a ferroresonant electric power circuit. IEEE Trans Power Deliv 6(2):866-872

56. Corea-Araujo JA, González-Molina F, Martínez JA, BarradoRodrigo JA, Guasch- Pesquer L (2014) Tools for characterization and assessment of ferroresonance using 3-D bifurcation diagrams. IEEE Trans Power Deliv 29(6):2543-2551

57. Amarab FB, Dhifaouib R (2011) Study of the periodic ferroresonance in the electrical power networks by bifurcation diagrams. Electr Power Energy Syst 33(1):61-85

58. Jordan DW, Smith P (2007) Nonlinear ordinary differential equations: an introduction for scientists and engineers, 4th edn. Oxford University Press, Oxford

59. Ben-Tal A, Shein D, Zissu S (1999) Studying ferroresonance in actual power systems by bifurcation diagram. Electr Power Syst Res 49(3): 175-183

60. Teschl G (2012) Ordinary differential equations and dynamical systems. American Mathematical Society, Providence (Author's preliminary version)

61. Cazacu E, Ioniţă V, Petrescu L (2017) An efficient method for investigating the ferroresonance of single-phase iron core devices. In: 10th international symposium on advanced topics in electrical engineering (ATEE), Bucharest, pp 363-368

62. Ben-Tal A, Kirk V, Wake G (2001) Banded chaos in power systems. IEEE Trans Power Deliv 16(1):105-110

63. Simon PL (2012) Differential equations and dynamical systems. Eotvos Lorand University, Institute of Mathematics, Department of Applied Analysis and Computational Mathematics

64. Miková Ľ, Gmiterko A, Hroncov D, (2016) State space representation of dynamical systems. Am J Mech Eng 4(7):385-389

65. Moses P, Masoum M (2009) Modeling subharmonic and chaotic ferroresonance with transformer core model including magnetic hysteresis effects. WSEAS Trans Power Syst 4:361-371

66. Kolańska-Płuska J, Grochowicz B (2016) Modelling of a non-linear coil with loss in iron using the Runge-Kutta methods. Arch Electr Eng 65(3):527-539

67. Milicevic K, Lukacevic I, Flegar I (2009) Modeling of nonlinear coil in a ferroresonant circuit. Electr Eng (Archiv fur Elektrotechnik) 91:51-59

68. Benabou A, Clénet S, Piriou F (2003) Comparison of preisach and Jiles-Atherton models to take into account hysteresis phenomenon for finite element analysis. J Magn Magn Mater 261(12):139-160

69. Li P, Chen L, Wu R, Tenreiro Machado JA, Lopes AM, Yuan L (2018) Robust asymptotic stability of interval fractional-order nonlinear systems with time-delay. J Franklin Inst 355(15):7749-7763

70. Dassios IK, Baleanu DI (2018) Caputo and related fractional derivatives in singular systems. Appl Math Comput 337:591-606

71. Jakubowska A, Walczak J (2015) Analysis of the transient state in a circuit with supercapacitor. Pozn Univ Technol Acad J Electr Eng $81: 27-34$
72. Walczak J, Jakubowska A (2014) Analysis of parallel resonance RLC circuit with supercapacitor. Comput Appl Electr Eng 12:30 37

73. Mitkowski W, Skruch P (2013) Fractional-order models of the supercapacitors in the form of RC ladder networks. Bull Pol Acad Tech 61(3):580-587

74. Sierociuk D, Sarwas G, Twardy M (2013) Resonance phenomena in circuits with ultracapacitors. In: 12th international conference on IEEE environment and electrical engineering (EEEIC). Wroclaw, Poland, pp 197-202

75. Schafer I, Kruger K (2008) Modelling of lossy coils using fractional derivatives. J Phys D Appl Phys 41:045001

76. Schafer I, Kruger K (2006) Modelling of coils using fractional derivatives. J Magn Magn Mater 307:91-98

77. Sowa M (2018) DAQ-based measurements for ferromagnetic coil modeling using fractional derivatives. 2018 International interdisciplinary Ph.D. workshop (IIPhDW) (IEEE), pp 91-95

78. Sowa M (2018) A harmonic balance methodology for circuits with fractional and nonlinear elements. Circuits Syst Signal Process 37(11):4695-4727

79. Sowa M (2018) A local truncation error estimation for a SubIval solver. Bull Pol Acad Sci Techn Sci 66(4):475-484

80. Sowa M, Kawala-Janik A, Bauer W (2018) Fractional differential equation solvers in octave/matlab. In: Conference: 2018 23rd international conference on methods and models in automation and robotics (MMAR)

81. Sowa M (2018) Application of SubIval in solving initial value problems with fractional derivatives. Appl Math Comput 319:86-103

82. Sowa M (2014) A subinterval-based method for circuits with fractional order elements. Bull Pol Acad Sci Techn Sci 62(3):449-454

83. Garrappa R (2015) Trapezoidal methods for fractional differential equations: theoretical and computational aspects. Math Comput Simul 110:96-112

84. Garrappa R (2018) Numerical solution of fractional differential equations: a survey and a software tutorial. Mathematics 6(2):16

Publisher's Note Springer Nature remains neutral with regard to jurisdictional claims in published maps and institutional affiliations. 